\title{
Zdravice k životnímu jubileu prof. RNDr. Antonína Přichystala, DSc.
}

\author{
Greetings for the jubilee of life \\ prof. RNDr. Antonín Přichystal, DSc.
}

\section{Lenka Lisá}

Zdá se to neuvěřitelné, ale $\mathrm{v}$ letošním roce oslaví pan profesor Antonín Přichystal kulaté životní jubileum. Proč neuvěřitelné? Protože ten člověk zkrátka vůbec na ten věk nevypadá a taky se tak nechová. Nepotkali byste jej jako starého zachmuřeného profesora s hůlkou, brýlemi a bradkou. Ty brýle sice sedí, ale jako vždy vystupuje jako mírný usměvavý člověk s lišáckým úsměvem a zdá se, že popoběhnout na šalinu mu žádný problém nedělá a ani se u toho nezadýchá.

Narodil se v roce 1950 v Třebčíně u Olomouce a je to srdcem typický petrograf. Jako asi většina regionálních geologů to ve své kariéře $\mathrm{v}$ komunistickém Československu neměl lehké. Geologové museli pracovat s přesnými mapami a ty se tzv. fasovaly. Byli to tedy lidé pod drobnohledem tehdejší vlády, at’ chtěli nebo nechtěli. První zkušenosti pan profesor, tehdy ovšem zcela obyčejný geolog, sbíral nejen na expedici v Mongolsku při práci u firmy Mongol-čechoslovak metall ale zároveň také na dnešní geologické službě, tehdy ovšem Ústředním ústavu geologickém v Brně, kde pracoval s Jindrou Hladilem nebo Jirkou Otavou, a to jako petrograf a geochemik a vulkanolog v letech 1975-1987. Určitě zásadním přelomem v jeho životě byla účast na letní školy Volcanisme et Géothermie, Université de la Réunion v Saint Denis, ostrov Réunion v roce 1985, kde měl možnost studovat vulkanity v rozhodně jiném měřítku než u nás ve střední Evropě. Tyto znalosti potom využil i ve své profesorské práci. Kvůli personálně politickým důvodům nebylo jednoduché uchytit se a udržet se na Masarykově univerzitě v Brně (tehdy Univerzita J. E. Purkyně), ale díky prof. Musilovi mu to nakonec bylo dopřáno. Zde zasvětil do tajů regionální geologie doslova stovky studentů, z nichž desítky potom vedl jako své studenty v bakalářském, magisterském nebo doktorském studiu od roku 1987 až dodnes, to znamená více jak tři desítky let. Za svou kariéru byl několikráte vedoucím katedry geologie a paleontologie PřF MU v Brně, vedoucí sekce věd o zemi na PřF MU v Brně nebo členem její oborové rady.

Během své kariéry také pochopil, že to co v naší republice chybí je užší spolupráce mezi geology a archeology a že on je schopen se svým zaměřením tuto mezeru vyplnit. Dal se tedy na nelehkou kariéru petroarcheologa. Proč zase nelehkou? Petroarcheogie je sice věda na úrovni ostatních geologických disciplín, ale pro geology byl od té doby ten, co dělá archeologii 


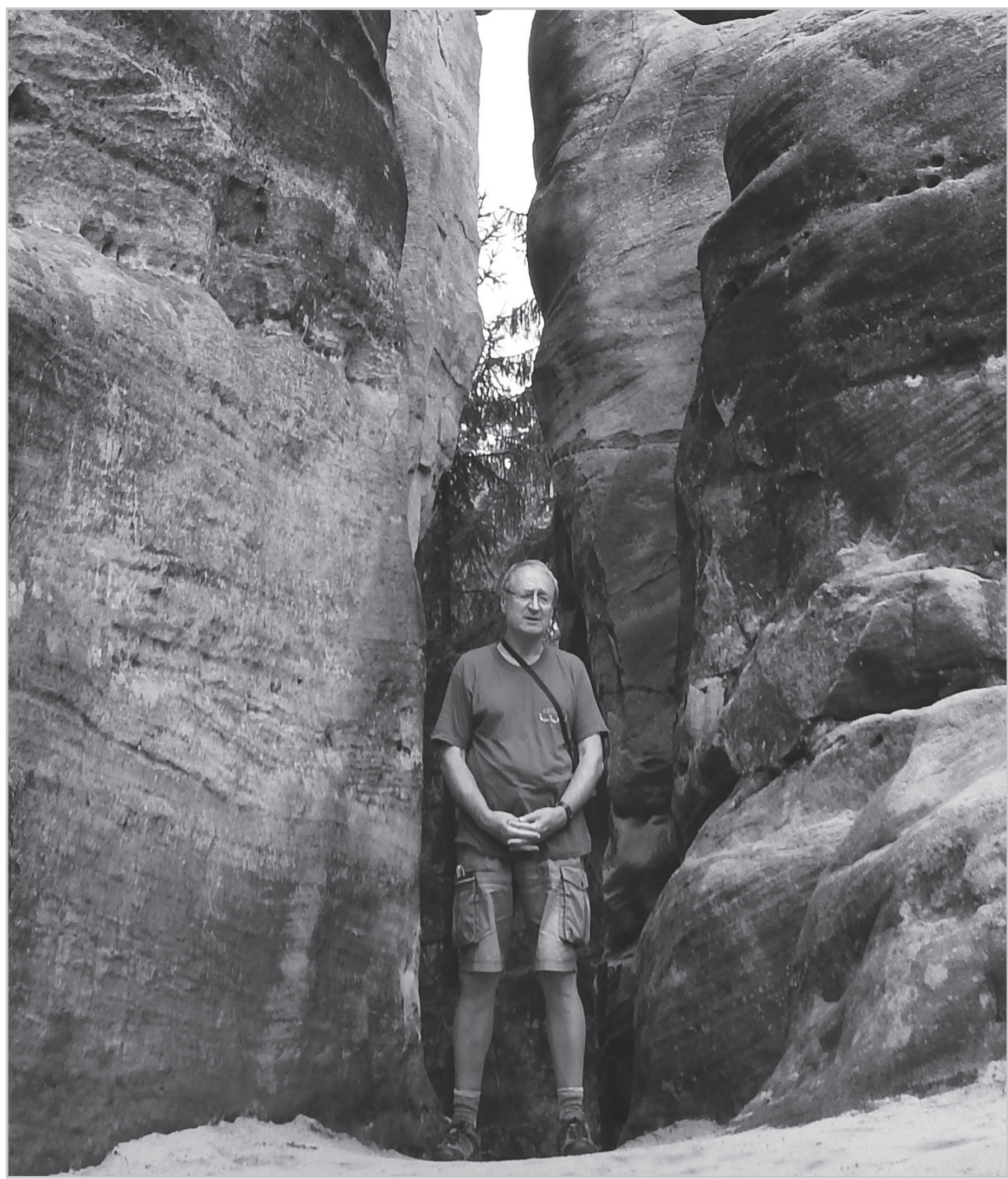


a pro archeology, ten co dělá geologii. Zkrátka někde na pomezí. Navíc byl ve svém oboru relativně sám a většina studentů, které vychoval, v jeho šlépějích vlastně nakonec nešla. Přesto se však do historie vývoje této disciplíny již ted' nesmazatelně zapsal například svou obsáhlou publikací „Kamenné suroviny v pravěku východní části střední Evropy“, která je celosvětově uznávaná (Přichystal 2009).

První setkání, které se mi vybavuje, je asi z přednášek. Jelo se celkem monotónně podle „Mísaře“ (Mísař 1987), zelené knihy regionální geologie, a jedinou legrácku, kterou si vždy tak odměřený a celkem nekompromisní profesor dovolil, bylo, když na nás jednou vybafnul anglicky a celou látku také v angličtině odpřednášel. Nebo ten jeho pověstný kufř́ík s různými typy vápenců a silicitů. Při letních terénech po Čechách, Moravě a Slezsku a při výjezdech do Slovinska jsme však záhy zjistili, že to není zas až takový suchar a že je to sportovec, který každé ráno cvičí, leze do jeskyní a umí hrát hezky na kytaru. A nejen že umí být zábavný, ale dá se na něj spolehnout. Možná to mne vedlo kdysi k tomu vybrat si jej za svého školitele. Nic mi nedaroval jenom tak, ale poznámka u obhajob o mé tvrdohlavosti a samostatnosti mi byla vlastně odměnou. Učil nás publikační morálce, která bohužel dnes již není takovou samozřejmostí. Pan profesor mne vlastně prováděl celou mou vědeckou kariérou, a to doslova i v posledních letech. Brali jsme jej vždycky za jakéhosi patrona geologie, bez kterého bychom si ten barák ani nedovedli představit. Až nedávno mne celkem vyděsilo poznání, že nám je dnes tolik, kolik bylo jemu, když nám přednášel. Měli jsme k němu ovšem vždy takový respekt, že si musím klást otázku, zda bychom i my dnes uspěli a vytvořili si v očích studentů takové renomé, jaké si on utvořil u nás.

\section{Použitá literatura}

Misař, Z. 1987: Regionální geologie světa. Praha: Academia.
Přichystal, A. 2009: Kamenné suroviny v pravěku východní části střední Evropy. Brno: Masarykova univerzita.

\section{Výběrová bibliografie prof. RNDr. Antonína Přichystala, DSc. 2010-2019}

\section{Článek v odborném periodiku}

Přichystal, A. 2010: Classification of lithic raw materials used for prehistoric chipped artefacts in general and siliceous sediments (silicites) in particular: the Czech proposal. Archeometriai Mühely, Budapest VII/3, 177-182.

Prichystal, A. 2018: State of arts: the Carpathian obsidians in the Czech Republic. Archeometriai Mühely/Archaeometry Workshop XV/3, 231-240.
Prrichystal, A. 2018: Artefacts Made from Siliceous Rocks of Polish Origin on Prehistoric Sites in the Czech Republic. Archaeologia Polona 56/1, $35-48$.

Přichystal, A. 2018: Amfibolické metabazity z Českého masivu jako dominující suroviny neolitických broušených nástrojů ve střední Evropě. Acta archaeologica Opaviensia 5, 207-222. 


\section{Odborná kniha}

Prichystal, A. 2013: Lithic raw materials in prehistoric times of eastern Central Europe. Brno: Masarykova univerzita.

\section{Kapitola v knize}

Přichystal, A. 2010: Suroviny a jejich zdroj. Kamenná štípaná industrie. In: M. Šmíd, Hrad u Bílovic. Hradisko z pozdní doby kamenné nad Běleckým mlýnem. Archeologické památky střední Moravy svazek 18 Olomouc: Archeologické centrum Olomouc, 70-74.

Prichystal, A. 2010: Raw material determination of chipped artefacts from graves of the Bell Beaker culture at Samborzec, Poland. In: J. Budziszewski - P. Wlodarczak, Kultura pucharów dzwonowatych na Wyzynie Malopolskiej. Kraków: Instytut Archeologii i Etnologii Polskiej Akademii Nauk, 245-247.

Prichystal, A. 2010: Kralice nad Oslavou v geologické minulosti. In: J. Mitáček a kol., Kralice nad Oslavou. Kralice nad Oslavou: Obec Kralice nad Oslavou, 9-24.

Prichystal, A. 2010: Geologické a přírodní poměry Ratíškovic. In: J. Mitáček - J. Čejka (eds.), Ratíškovice, minulostí slovácké obce. Ratíškovice: Obec Ratíškovice, 7-24.

Prichystal, A. 2011: Non-flint industry. In: J. Svoboda (ed.), Pavlov. Excavations 2007-2011. The Dolní Věstonice Studies 18. Brno: AÚ AV ČR v Brně, 168-169.

Přichystal, A. 2011: Geologie území a petrografická charakteristika rohovců z Krumlovského lesa. In: M. Oliva (ed.), Pravěké hornictví v Krumlovském lese. Vznik a vývoj industriálně-sakrální krajiny na jižní Moravě. Anthropos 32, N.S. 24. Brno: Moravské zemské muzeum, 385-392.

Prichystal, A. 2011: Geologie brněnského prostoru. In: R. Procházka (ed.), Dějiny Brna 1. Od pravěku k ranému středověku. Brno: Statutární město Brno, 17-40.
Přichystal, A. 2012: Suroviny kamenné industrie z kralického pohřebiště. In: M. Šmíd, Kostrové a žárové pohřebiště kultury s lineární keramikou v Kralicích na Hané, střední Morava. Pravěk NǨ. Supplementum 25. Brno: Ústav archeologické památkové péče Brno, 90-94, 156-158, 172-173.

Přichystal, A. 2013: Suroviny kamenné industrie z kralického pohřebiště. In: M. Šmíd, Kralice na Hané. Birituální pohřebiště kultury s lineární keramikou. Archeologické památky střední Moravy 20. Olomouc: Archeologické centrum Olomouc, 61-66, 98-99.

Prichystal, A. 2013: Lithic raw material base of the Middle Palaeolithic settlement in Bojnice. In: P. Neruda - L. Kaminská, Neanderthals at Bojnice in the context of Central Europe. Anthropos 36, N.S. 28. Brno - Nitra: Moravské zemské muzeum, Archeologický ústav SAV, 182-187.

Přichystal, A. 2013: Geologie Mikulova. In: M. Svoboda a kol., Mikulov. Historie, kultura, lidé. Praha: Nakladatelství Lidové noviny, 15-21.

Přichystal, A. 2014: Přírodní podmínky - neživá příroda Rajhradu. In: K. Altman - I. Durec (eds.), Kniha o Rajhradě. Dějiny města od nejstarších dob. Rajhrad: Město Rajhrad, 10-23.

Přichystal, A. 2014: Petrografické určení surovin kamenných artefaktů $\mathrm{z}$ raněstředověké lokality Olomouc-Nemilany. In: R. Přichystalová - M. Kalábek (eds.), Raněstředověké pohřebiště Olomouc-Nemilany. Katalog. Brno: Masarykova univerzita. 199-201.

Prrichystal, A. 2014: Kamenná surovina zo Skalice a okolia. In: V. Drahošová (ed.), Skalica: Mesto Skalica a Záhorské múzeum, 494-497. 
Přichystal, A. 2014: Geologická minulost Bohunic. In: A. Crha (ed.), Z historie Bohunic. Brno: PhDr. Jitka Crhová, 19-28.

Prichystal, A. 2015: Key raw materials for Neolithic shoe-last celts and axes in Central Europe: their sources and distribution. In: T. Kerig - S. Shennan (eds.), Connecting Networks. Characterising Contact by Measuring Lithic Exchange in the European Neolithic. Oxford: Archaeopress Publishing Ltd, 1-7.
Přichystal, A. 2017: Zdroje kamenných surovin. In: D. Parma (ed.), Archeologie střední a mladší doby bronzové na Vyškovsku. Brno: Ústav archeologické památkové péče Brno. 151-152.

Přichystal, A. 2018: Geologická stavba Pohořelicka. In: E. Kordiovský - M. Svoboda (eds.), Město Pohořelice. Pohořelice: Město Pohořelice, 79-86.

Přichystal, A. 2019: Kamenné artefakty Býčí skály. In: M. Golec (ed.), Fenomén Býčí skála. Krajina, jeskyně, člověk. Praha: Nakladatelství Lidových novin, 133-136.

\section{Článek v odborném periodiku s kolektivní účastí}

Bartik, J. - Kopacz, J. - Nývltová Fišáková, M. - Přichystal, A. - Śebela, L. - Škrdla, P. 2018: The Question of Chert Exploitation by Bell Beaker People on Stránská skála Hill (Brno-Slatina, Czech Republic). Journal of Neolithic Archaeology 2018/4, 185-202.

Bartik, J. - Škrdla, P. - Šebela, L. - Přrchystal, A. - Nejman, L. 2019: Mining and processing of the Stránská skála-type chert during the Late Neolithic and Early Eneolithic periods. Archeologické rozhledy LXXI/3, 373-414.

Bronowicki, J. - Přichystal, A. 2015: Radlowice, pow. olawski (wczesnobrazowy import morawskiej brekcji rogowcowej na Ślasku). Silesia Antiqua 50, 405-408.

Burgert, P. - Přrchystal, A. - Prokeš, L. - Petřik, J. - Hušková, S. 2016: The origin of obsidian in prehistoric Bohemia. Archeologické rozhledy LXVIII/2, 224-234.

Burgert, P. - Přrchystal, A. - Prokě̌, L. - Petř̀k, J. - Hušková, S. 2017: The origin and distribution of obsidian in prehistoric Bohemia. BULGARSKO E-SPISANIE ZA ARKHEOLOGIYA-BULGARIAN E-JOURNAL OF ARCHAEOLOGY 7/1, 1-15.

Čuláková, K. - Eigner, J. - Metlička, M. - Přichystal, A. - Řezáč, M. 2012: Horské mezolitické osídlení u Javoří Pily, obec Modrava, okr. Klatovy. Archeologie ve stř̌edních Čechách 16/1, 19-28.

Doláková, N. - Roszková, A. - Přichystal, A. 2010: Palynology And Natural Environment In The Pannonian To Holocene Sediments Of The Early Medieval Centre Pohansko Near Breclav (Czech
Republic). Journal of Archaeological Science $37 / 10,2538-2550$.

Dominguez-Bella, S. - Cassen,S. - Pétrequin, P. - Přichystal, A. - Martinez, J. - Ramos, J. - Medina, N. 2016. Aroche (Huelva, Andalucia): a new Neolithic axehead of Alpine jade in the southwest of the Iberian Peninsula. Archaeological and Anthropological Sciences 8/1, s. 205-222.

Dufek, J. - Malyková, D. - Popelka, M. - Přichystal, A. 2016: Stopy dálkových kontaktů na neolitickém sídlišti v Kolíně-Štáralce. Archeologie ve středních Čechách 20/2, 935-957.

Eigner, J. - Fröhlich, J. - Přichystal, A. 2014: Eneolitická sekera z neobvyklého silicitu z píseckého muzea. Archeologie ve středních Čechách 18/1, 87-89.

Eigner, J. - Přichystal, A. 2015: Štípaná kamenná industrie kultury nálevkovitých pohárů z Litoměřic, býv. Höringovy pískovny. Archeologie ve středních Čechách 19/1, 507-514.

Eigner, J. - Přichystal, A. - Doběs, M. 2017: Časný a starší eneolit Kadaňska a horního Pohří pohledem kamenné industrie. Archeologie ve středních Čechách 21/2, 577-615.

Fojt, B. - Prrichystal, A. 2015: Paragenetická charakteristika železitých konkrecí z lokality „Zukalův kopec" na katastru obce Mokrá-Horákov. Acta Musei Moraviae, Sci. geol. 100/1, 61-68.

Frýbová, P. - Gadas, P. - Přichystal, A. - Všianský, D. - Hadacz, R. - Hlavsa, P. 2018: The provenance of serpentinite tools in the Corded Ware culture of Moravia. Geological Quarterly 62/3, 563-578. 
Havelcová, M. - Machovič, V. - Linhartová, M. - Lapčák, L. - Přichystal, A. - Dvořák, Z. 2016: Vibrational spectroscopy with chromatographic methods in molecular analyses of Moravian amber samples (Czech Republic). Microchemical Journal 128/ September, 153-160.

Janák, V. - Furmanek, M. - Přichystal, A. 2018: Petroarcheologický výzkum neolitu a eneolitu ve Slezsku. Acta Archaeologica Opaviensia 5. 7-31.

Janák, V. - Kejual, P. - Mareček, J. - Němcová, J. Přichystal, A. 2018: Suroviny kamenné industrie z Hradce nad Svitavou v kontextu surovinové základny kultury s lineární keramikou na moravsko-českém pomezí. Acta Archaeologica Opaviensia 5, 165-185.

Janák, V. - Papáková, K. - Přichystal, A. - Kováčik, P. - Knápek, A. - Rataj, P. - Boček, J. - Hořínková, A. 2017: Broušená a štípaná kamenná industrie z neolitického sídliště Pustějov - „Dolní role“ v letech 2011-2012. Časopis Slezského zemského muzea, série B 65/3, 201-222.

Janák, V. - Papáková, K. - Přichystal, A. - Kováčì, P. Rataj, P. - Hořinková, A. 2016: Neolitické osídlení v okolí Studénky a úloha zdejšího mikroregionu kultury s lineární keramikou v distribuci silicitů krakovsko-čenstochovské jury. Slovenská archeológia LXIV/1, 1-63.

Janák, V. - Přichystal, A. 2019: Surovinová základna broušené industrie kultury s lineární keramikou v českém a polském Horním Slezsku. Silesia Antiqua 51/1, 7-43.

Jarošová, M. - Lisá, L. - Přichystal, A. - Parma, D. Petr, L. - Kos, P. 2010: Geoarcheologický výzkum halštatské zemnice v Modřicích u Brna. Geologické výzkumy na Moravě a ve Slezsku. XVII/1-2, 39-45.

Kasztovszky, Z. - Prichystal, A. 2018: An overview of the analytical techniques applied to study the Carpathian obsidians. Archeometriai Mühely/Archaeometry Workshop XV/3, 187-196.

Kopacz, J. - Přichystal, A. - Šebela, L. 2015: L'industrie lithique tailée Campaniforme dans son milieu oriental. La Moravie, la Bohéme et la question de „reflux migratoire“. Acta Archaeologica Carpathica 50/1, 33-67.

Kopacz, J. - Přichystal, A. - Šebela, L. 2016: Forerunners of the New Epoch in Lithic Chipped Industries of the Moravian Young Eneolithic. Musaica archaeologica I/1, 105-118.

Kropáč, K. - Dolníček, Z. - Přichystal, A. - Lehotský, T. - Koštuř́ková, T. - Jakubál, J. 2015: Nový výskyt menilitového souvrství u Dřevohostic. Geologické výzkumy na Moravě a ve Slezsku XXII/1-2, 5-10.

Krmíček, L. - Přichystal, A. Šešulka, V. 2010: Geofyzikální sledování a petrologická charakteristika permského „melafyru“ na jižním okraji orlické pánve u Předního Arnoštova. Zprávy o geologických výzkumech v roce 2009, č. 1, 229-233.

Macháček, J. - Balcárková, A. - Čáp, P. - Dresler, P. - Přichystal, A. - Přichystalová, R. - Schuplerová, E. - Sládek, V. 2014: Velkomoravská rotunda z Pohanska u Břeclavi. Památky archeologické CV, 87-153.

Mlejnek, O. - Škrdla, P. - Přichystal, A. 2012: Ondratice I/Želeč - an Early Upper Palaeolithic site in central Moravia. Archäologisches Korrespondenzblatt 42/3, 295-314.

Mrázek, J. - Přichystal, A. 2011: Paleozoické horniny jako možné suroviny kamenných artefaktů na eneolitických hradištích Prostějovska. Př́rodovědné studie Muzea Prostějovska 12-13/1, 31-66.

Nejman, L. - Wood, R. - Wright, D. - Lisá, L. - Nerudová, Z. - Neruda, P. - Přichystal, A. - Svoboda, J. 2017: Hominid visitation of the Moravian Karst during the Middle-Upper Paleolithic transition: New results from Pod Hradem Cave (Czech Republic). Journal of Human Evolution 108/July, 131-146.

Nejman, L. - Wright, D. - Lisá, L. - Doláková, N. Horáček, I. - Novák, J. - Wood, R. - Pacher, M. Sázelová, S. - Holub, M. - Přichystal, A. - Nývltová Fišáková, M. - Bajer, A. 2013: Hominids and palaeoenvironments in the Moravian Karst during Marine Isotope Stage 3: new excavations in Pod Hradem Cave, Czech Republic. Antiquity, Antiquity Publications 87/337.

Nerudová, Z - Přichystal, A. 2012: Rozbor kamenné štípané industrie ze sídliště Kosoř (okr. Praha-západ). Sborník prací filozofické fakulty brněnské univerzity M 17, s. 9-25.

Nerudová, Z - Neruda, P. - Přichystal, A. 2013 : A unique raw material from Early Upper Palaeolithic layers in the Pod hradem Cave (Moravian Karst, Czech Republic) - interpretative problems. Anthropologie L/4, 463-474. 
Nerudová, Z - Přichystal, A. - Neruda, P. 2012: Revize nálezů z jeskyně Pod hradem v Moravském krasu. Archeologické rozhledy LXIV/1, 136-152.

Ondráček, J. - Přichystal, A. 2017: Svory jako surovina raně středověkých žernovů na hradišti Staré Zámky v Brně-Líšni. Acta Musei Moraviae. Scientiae sociales CII/2, 39-150.

Pétrequin, P. - Cassen, S. - Chevillot, Ch. - Errera, M. Pailler, Y. - Pétrequin, A-M. - Přichystal, A. - Prodéo, F. 2015: La production des anneux-disques alpins pendant les VIe et Ve millénaires av. J.-C. et le Mont Viso. Revue Archéologique de l'Est 64/40, 259-302.

Petřik, J. - Přichystal, A. 2011: Petroarcheologie ostatní kamenné industrie z lokality Tell Arbid Abyad, severní Mezopotámie (Sýrie). Geologické výzkumy na Moravě a ve Slezsku XVII/2, 174-180.

Pracný, P. - Faimon, J. - Všianský, D. - Přichystal, A. 2019: Evolution of $\mathrm{Mg} / \mathrm{Ca}$ and $\mathrm{Sr} / \mathrm{Ca}$ ratios during the experimental dissolution of limestone. Chemical Geology 523/SEP 30, 107-120.

Prokeš, L. - Vašinová Galiová, M. - Hušková, S. - Vaculovič, T. - Hrdlička, A. - Mason, A. Z. - Neff, H. - Prichystal, A. - Kanický, V. 2015: Laser microsampling and multivariate methods in provenance studies of obsidian artefacts. Chemical Papers $69 / 6,761-778$.

Prokop, J. - Losos, Z. - Přichystal, A. 2012: Chemické složení turmalínu z hydrotermálně alterovaných vulkanitů u obce Hlásnice v jižní části šternbersko-hornobenešovského pruhu. Geologické výzkumy na Moravě a ve Slezsku XIX/1-2, 109113.

Přichystal, A. - Burgert, P. - Gadas, P. 2019: Marble from Neolithic quarries at the Bílý Kámen Hill near Sázava (Czech Republic) and its petrographic-geochemical characterization. Geological Quarterly 63/4, 811-821.

Přichystal, A. - Kovář, J.J. - Kuča, M. 2011: Unikátní pravěká sekerka ze sbírek jesenického muzea. Vlastivědný věstník moravský 63/4, 331-334.

Přichystal, A. - Kováŕ, J. J. - Kuča, M. 2012: A Nephrite Axe from the Jeseník Museum. Časopis Slezského zemského muzea - série B LX/1, 153-159.

Přichystal, A. - Slobodní, M. 2011: Brněnský křemenný val. Geologické výzkumy na Moravě a ve Slezsku XVIII/2, 78-152.
Přichystal, A. - Šebela, L. 2011: Kultura zvoncovitých pohárů ve východní části střední Evropy a silicitové sekery. Živá archeologie - REA 2011/13, 52-57.

Přichystal, A. - Šmíd, M. 2011: Kamenná industrie z birituálního pohřebiště LnK v Kralicích na Hané, okr. Prostějov. Praehistorica XXIX/1, 323-342.

Přchystal, A. - Škrdla, P. 2014: Kde ležel hlavní zdroj obsidiánu v pravěku střední Evropy? Slovenská archeológia LXII/2, 215-226.

Přichystal, A. - Valová, P. 2010: Provenience metabazitů kamenné broušené industrie z neolitického sídliště u Těšetic-Kyjovic. Geologické výzkumy na Moravě a ve Slezsku XVII/1, 156-161.

Slobodnik, M. - Přichystal, A. - Gadas, P. - Kontár, M. - Morávek, R. 2010: Genetické aspekty vzniku křištálů v sileziku, severní Morava. Bulletin mineralogicko-petrologického oddělení Národního muzea v Praze 18/2, 32-42.

Slobodnik, M. - Přichystal, A. - Morávek, R. 2010: Geneze křemenných žil u Velké Kraše v sileziku. Geologické výzkumy na Moravě a ve Slezsku XVII/1-2, 172-174.

Slobodnik, M. - Přichystal, A. 2017: Provenience křištálových artefaktů z aurignacké stanice Nová Dědina u Kroměříže na základě studia fluidních inkluzí. Přehled výzkumů 58/1, 9-18.

Stolz, D. - Malyková, D. - Kovačiková, L. - Přichystal, A. - Řidký, J. 2018: Sídliště kultury s vypíchanou keramikou na silničním obchvatu v Kolíně-Štítarech. Analýza kamenné industrie a zvířecích kostí, radiokarbonové datování a celkové zhodnocení. Archeologie ve středních Čechách 22/1, 31-69.

Šebela, L. - Přichystal, A. 2014: Silicitové dýky na území České a Slovenské republiky. Předběžná studie. Studia Archaeologica Brunensia 19/1, 67-94.

Šebela, L. - Přichystal, A. - Humpolová, A. - Prokeš, L. 2015: Eneolithic hillfort Starý Zámek near Jevišovice. A contribution to lithic chipped industry research in southwestern Moravia. Přehled výzkumů 56/1, s. 59-117.

Šebela, L. - Škrdla, P. - Přrchystal, A. - Kopacz, J. 2016: Dílna kultury zvoncovitých pohárů na zpracování rohovce typu Stránská skála (Brno, katastrální území Slatina). Musaica archaeologica I/1, 119-128.

Šešulka, V. - Drápalová, R. - Přichystal, A. - Všianský, D. 2012: Nové poznatky o neovulkanitu v Pohoři 
u Oder (okres Nový Jičín). Geologické výzkumy na Moravě a ve Slezsku XIX/1-2, 48-52.

Šě̌ulka, V. - Sedláková, I. - Bábek, O. - Přichystal, A. 2014: Identification of a buried Late Cenozoic maar-diatreme structure (North Moravia, Czech Republic). Geologica Carpathica. Veda 65/6, 471-479.

Šmíd, M. - Biško, R. - Přichystal, A. 2017: Objekt s doklady zpracování rohovce typu Stránská skála a keramikou zdobenou brázděným vpichem z Brna-Maloměřic. Pravěk NŘ 25, 5-26.

Ulrych, J. - Ackerman, L. - Balogh, K. - Hegner, E. Jelinek, E. - Pécskay, Z. - Přichystal, A. - Upton, B. G. J. - Zimák, J. - Foltýnová, R. 2013: Plio-Pleistocene basanitic and melilitic series of the Bohemian
Massif: K-Ar ages, major/trace element and Sr-Nd isotopic data. Chemie der Erde - Geochemistry 73/4, 429-450.

Vlačiky, M. - Michalik, T. - Nývltová Fišáková, M. - Nývlt, D. - Moravcová, M. - Králik, M. - Kovanda, J. - Péková, K. - Príchystal, A. - Dohnalová, A. 2013: Gravettian occupation of the Beckov Gate in Western Slovakia as viewed from the interdisciplinary research of the Trenčianske Bohuslavice - Pod Tureckom site. Quaternary International 2013/294, 41-60.

Trampota, F. - Jarošová, I. - Nývltová Fišáková, M. Přichystal, A. 2012: Lengyelská kultura ve Střelické kotlině. Študijné zvesti Archeologického ústavu SAV 51, 89-174.

\section{Odborná kniha s kolektivní účastí}

Kolář, J. - Dobisiková, M. - Dreslerová, G. - Drozdová, E. - Fojtová, M. - Hložek, M. - Gregerová, M. - Přichystal, A. - Urbanová, K. - Wagenknechtová, M. 2011: Kultura se šňůrovou keramikou v povodí říčky Hané na střední Moravě: pohřební areály z prostoru dálnice D1 v úseku Vyškov - Mořice a dalších staveb. Pravěk NŘ. Supplementum 23. Brno: Ústav archeologické památkové péče.

Kopacz, J. - Přichystal, A. - Šebele, L. 2014: Lithic Chipped Industry of the Young Eneolithic in Moravia and Czech Silesia. Brno: Archeologický ústav AV ČR.

\section{Kapitola v knize s kolektivní účastí}

Biró, K. - Pétrequin, P. - Errera, M. - Přichystal, A. Trnka, G. - Zalai-Gaál, I. - Osztás, A. 2017: Des Alpes a l'Europe centrale (Autriche, République tcheque, Slovaquie et Hongrie). In: P. Pétrequin - E. Gauthier - A-M. Pétrequin (eds.), JADE. Objets-signes et interprétations sociales des jades alpins dans l'Europe néolithique. Les Cahiers de la MSHE Ledoux no. 27. Besancon: Presses universitaires de Franche-Comté, 431-466.

Cinquetti, M. - Pétrequin, P. - Costa, E. - Errera, M. Přichystal, A. 2017: Anneaux-disques et parures en
Šmíd, M. - Dreslerová, G. - Přichystal, A. 2010: Hrad u Bílovic. Eneolitické hradisko na Prostějovsku. Pravěk NŘ. Supplementum 21. Brno: Ústav archeologické památkové péče.

Šmíd, M. - Přichystal, A. 2015: Eneolitická hradiska na Prostějovsku. Ohrozim - Čubernice a Prostějov-Čechovice - Čechovsko. Pravěk NŘ. Supplementum 29. Brno: Ústav archeologické památkové péče.

paragonite. In: P. Pétrequin - E. Gauthier - A-M. Pétrequin (eds.), JADE. Objets-signes et interprétations sociales des jades alpins dans l'Europe néolithique. Les Cahiers de la MSHE Ledoux no. 27. Besancon: Presses universitaires de Franche-Comté, 703-728.

Errera, M. - Pétrequin, P. - Pétrequin, A-M. - Vaquer, J. - Přichystal, A. 2017: Les néphrites alpines at pyrénéennes. Prospections, référentiels et reconnaissance spectroradionétrique. In: P. Pétrequin - E. Gauthier - A-M. Pétrequin (eds.), JADE. Objets- 
-signes et interprétations sociales des jades alpins dans l`Europe néolithique. Les Cahiers de la MSHE Ledoux no. 27. Besancon: Presses universitaires de Franche-Comté, 87-112.

Nerudová, Z - Přichystal, A. 2011: Kamenná štípaná industrie. In: M. Lička, Osídlení kultury s lineární keramikou v Kosoři, okr. Praha-západ. Fontes Archaeologici Pragenses 37. Praha: Národní muzeum v Praze, 78-86.

Pétrequin, P. - Pétrequin, A-M. - Errera, M. - Přrichystal, A. 2017: Les jadéitites de Syros (Cyclades, Grece). In: P. Pétrequin - E. Gauthier - A-M. Pétrequin (eds.), JADE. Objets-signes et interprétations sociales des jades alpins dans l`Europe néolithique. Les Cahiers de la MSHE Ledoux no. 27. Besancon: Presses universitaires de Franche-Comté, 25-46.

Petřik, J. - Přichystal, A. 2012: Petroarchaeological investigation of the so-called 'other stone industry' from Tell Arbid Abyad, SYRIA. In: R. Matthews - J. Curtis (eds.), Proceedings of the $7^{\text {th }}$ International Congress on the Archaeology of the Ancient Near East. Wiesbaden: Harrassowitz Verlag, 657-672.

Přichystal, A. - Kováúr, J. J. - Kuča, M. - Fridrichová, K. 2019: The jadeitite-omphacitite and nephrite axe- heads in Europe. The case of the Czech Republic. In: R. Glesser - D. Hofmann (eds.), Contacts, boundaries and innovation in the fifth millennium. Exploring developed Neolithic societies in central Europe and beyond. Leiden: Sidestone Press, 289-304.

Přichystal, A. - Šebela, L. 2013: The Bell Beaker culture in Eastern Central Europe and silicite (flint) axes. In: M. P. P. Martínez - L. Salanova (eds.), Current researches on Bell Beakers. Proceedings of the $15^{\text {th }}$ International Bell Beaker Conference: From Atlantic to Ural. Santiago de Compostela: Galician ArchaeoPots, 163-176.

Přichystal, A. - Všianský, D. 2012: Petroarcheologický výzkum kamenné industrie z Hoštic I, Hoštic IV a Ivanovic VI. In: A. Matějíčková - P. Dvořák (eds.), Pohřebiště z období zvoncovitých pohárů na trase dálnice D1 Vyškov - Mořice. Pravěk NŘ. Supplementum 24. Brno: Ústav archeologické památkové péče, 303-322.

Přichystal, A. - Šebela, L. 2015: Silicite daggers from the territories of the Czech Republic and Slovakia (a preliminary study). In: C. J. Frieman B. V. Eriksen (eds.), Flint daggers in prehistoric Europe. Oxford - Philadelphia: Oxbow Books, 133-148. 
